\title{
ПСИХОЛОГИЯ
}

DOI: 10.17805/trudy.2016.2.1

\section{ОРГАНИЗАЦИОННАЯ КУЛЬТУРА И СОВЛАДАЮЩЕЕ ПОВЕДЕНИЕ РАБОТНИКА}

\author{
К. В. Тащи \\ (Московский гуманитарный университет)
}

\begin{abstract}
Аннотация: Статья представляет собой аналитический обзор существующих современных исследований и литературных источников по проблеме представлений о совладающем поведении в рамках организационной, или корпоративной, культуры. Статья раскрывает понятия организационной культуры, совладающего поведения, и организационного стресса, а также содержит в себе аспекты, посвященные культуре безопасности работника.
\end{abstract}

Ключевые слова: организация; организационная культура; организационный стресс; стрессовая ситуация; трудная жизненная ситуация; совладающее поведение; копинг-стратегии; психология безопасности; безопасная среда

\section{ORGANIZATIONAL CULTURE AND EMPLOYEE'S COPING BEHAVIOR}

\author{
K. V. Tashchi \\ (Moscow University for the Humanities)
}

\begin{abstract}
The article provides an analytical review of the current research literature and other sources on the problem of representations of coping behavior within the corporate culture, examining the notions of «organizational culture», «coping behavior» and «organizational stress» and also covering some aspects of employee safety culture.
\end{abstract}

Keywords: organization; organizational culture; organizational stress; stressful situation; difficult situation in life; coping behavior; coping strategies; psychology of security; safe environment

\section{Введение}

Проблема преодолевающего поведения приобретает все большую популярность в зарубежной и отечественной психологии. Этому способствует повышение стрессогенности социальной жизни не только в сфере межличностных отношений, но и в трудовой деятельности человека, а также расширение спектра социальных и экономических кризисов. Поэтому в настоящее время одной из самых важных задач в сфере управления пер- 
соналом является помощь сотрудникам в формировании конструктивных поведенческих стратегий по преодолению организационного стресса.

На сегодняшний день одним из факторов, определяющих совладающее поведение в ситуациях организационного стресса, можно по праву считать корпоративную культуру, а анализ особенностей прогрессивных (в частности, западных) организаций показывает, что одной из них является хорошо проработанная и определенная культура и философия организации.

\section{Общее понятие организационной культуры}

Концепции социальной организации и организационной культуры широко представлены в работах Э. Шейна, К. Камерона и Р. Куинна, А.И.Пригожина, А. И. Кравченко и А. Н. Занковского. В общем виде под организационной культурой понимаются разделяемые членами организации определенные нормы и ценности, следствием принятия которых является определенное, соответствующее им поведение (Грачев, 2014). Организационная культура любого предприятия берет на себя целый ряд важных функций, начиная от создания у сотрудников чувства социальной стабильности и заканчивая повышением организационной эффективности. Отсутствие же единой организационной культуры может способствовать образованию разнообразных групповых субкультур, которые, в ряде случаев, могут значительно способствовать организационному разладу и снижению эффективности производства (Аберкромби, Хилл, Тернер, 2008).

Структура организационной культуры по Э. Шейну включает в себя три взаимосвязанных уровня: поверхностный (уровень артефактов), внутренний (уровень ценностей) и глубинный (уровень базовых предположений) (Шейн, 2002). Для глубокого и полного понимания организационной культуры необходима работа со всеми обозначенными уровнями, начиная от внешней атрибутики организации и заканчивая подсознательными установками и верованиями сотрудников. Сам же Шейн отводит ведущую роль последнему, глубинному уровню организационной культуры, считая, что именно на нем можно установить ее суть (там же).

На информационном уровне представления работников о возможных способах поведения в стрессовых ситуациях на рабочем месте представлены через совокупность имеющихся у них терминальных образов, которые включают в себя образы организационной среды, образы организационных ситуаций (в том числе и стрессовых) и образы работника («как я должен поступать в этой стрессовой ситуации»- в идеале, и «как я склонен обычно поступать в ней» - в реальности) (Грачев, 2008). Наиболее значимым среди них является образ ситуации жизнедеятельности, в котором синтезируются остальные образы, поэтому основным функ- 
циональным элементом организации, через который можно изучать проявления организационной культуры, следует рассматривать типовую организационную ситуацию, которая включает в себя и ситуации организационного стресса.

\section{Понятие стрессовой ситуации и совладающего поведения}

Проведенный анализ литературы позволяет констатировать отсутствие общепринятого понятия «стрессовая ситуация», однако, в целом, ее можно определить как вид неординарной социально-психологической ситуации, в том числе и профессионально-трудной ситуации, которая содержит объективные повышенные требования к адаптационным ресурсам человека, детерминирует изменения его психического состояния и качество взаимодействия в системе «субъект-ситуация». При этом в большинстве случаев стрессовая ситуация представляет собой разновидность именно социально-психологической ситуации в отличие от природных катаклизмов или экологических катастроф (Водопьянова, 2009).

Следует также отметить, что в литературе в качестве синонима стрессовой ситуации часто используется термин «трудная жизненная ситуация», однако, с нашей точки зрения, второе определение значительно шире, поскольку может включать в себя ситуации не только стрессового характера, но и другие, менее острые затруднения, встречающиеся на пути человека.

Проблема противодействия трудным жизненным ситуациям, получила свое развитие и отражение в понятии «копинг», или «психологическое преодоление»/«совладающее поведение». Появление и развитие этого термина в отечественной психологии можно проследить в работах Т.Л. Крюковой, Л. П. Гримака, С. К. Нартовой-Бочавер, В. А. Бодрова, Л. Г. Дикой, А.Б. Леоновой и др.

Т. Л. Крюкова определяет совладающее поведение как особое целенаправленное социальное поведение, которое обеспечивает продуктивность, здоровье и благополучие человека, и позволяет ему справляться со стрессом адекватными личностным особенностям и ситуации способами (Крюкова, 2013). Основным критерием для анализа специфики совладающего поведения выступает понятие выбора человеком способа действий в ситуации стресса, а также прогнозирование исхода осуществляемых действий, которые часто, особенно если речь идет о производственных организациях, могут нести за собой определенные последствия.

Наиболее используемой в исследованиях на сегодняшний день моделью совладающего поведения по-прежнему остается контекстуальная, или ситуационная модель Р. Лазаруса и С. Фолкмана, которая постепенно получает свое развитие в рамках интегративно личностно-ситуационного подхо- 
да. В частности, этот новый подход демонстрируют исследования Крюковой и ее коллег из Костромского университета (М. В. Сапоровская, С.А.Хазова, Е. В. Куфтяк и др.), которые основаны на методологии социальной контекстуализации совладающего поведения (правда, в основном в этих работах исследовался контекст не организационного, а семейного стресса). Суть данного подхода состоит в том, что люди отличаются по степени проявления стабильности их личностных особенностей в разных ситуациях, а ситуации отличаются друг от друга по тому, насколько они способствуют или препятствуют проявлению индивидуальных различий людей.

В качестве факторов выбора человеком того или иного типа совладающего поведения интегративный подход рассматривает: диспозиционный (личностный), динамический (ситуативный), регулятивный и экологический (социокультурный) факторы поведения субъекта (Крюкова, 2013). Следуя этой логике, влияние организационной культуры, ее норм и ценностей на поведение работника можно рассматривать как компонент регулятивного и социокультурного фактора.

\section{Совладающее поведение в организационной культуре}

Как указывалось выше, хорошо проработанная организационная культура обеспечивает реализацию целой группы функций, одной из которых, по мнению О. Е. Стекловой (Стеклова, 2007), является поддержание у работников чувства стабильности и безопасности.

С функциями организационной культуры связано, в том числе, выделение в ней регламентированной и нерегламентированной составляющих (Грачев, 2008). Так, огромную роль, связанную с любым производством, играет регламентированная активность, которая сопряжена с техникой безопасности, утвержденной на предприятии. Однако в современной литературе указывается на тот факт, что увеличение числа несчастных случаев на производстве может быть следствием не только уклонения от техники безопасности, но и выраженного организационного стресса (Водопьянова, 2009). Поэтому в любой организации существует и нерегламентированная составляющая организационной культуры, которая восполняет «пустоты» в функционировании организации, обеспечивая целостность и законченность всего процесса.

На основе подобного подхода, рассматривающего в качестве объекта работника, выполняющего профессиональную деятельность в определенных условиях, сформировалось отдельное направление психологической науки - психология безопасности, которая определяется М. А. Котиком как ветвь психологической науки, изучающая психические предпосылки злосчастных случаев, возникающих в процессе труда и других видов деятельности, и пути использования психологии для увеличения безопасно- 
сти деятельности (Котик, 1989).

На сегодняшний день дополнительные перспективы в исследовательских работах по безопасности труда дает организационный подход, широко представленный в работах А. А. Грачева (Грачев, 2014). Основой такого подхода является нацеленность на формирование ценностей безопасности, норм неопасного поведения и базисных представлений, реализующих ценности и нормы, посредством использования технологического и сценарного подходов. При этом, особое внимание при реализации организационного подхода автор предлагает уделять двум разновидностям трудных жизненных ситуаций, значимых в плане безопасности: происшествию - событию, которое приводит или может привести к несчастному случаю; и несчастному случаю - нежелательному событию, приводящему к смертельному исходу, травме или заболеванию работника (ГОСТ Р 12.0.006-2002) (Система стандартов ..., Электр. ресурс).

Помимо представления о поведении рядового работника, в любой организационной культуре должно отражаться и поведение высшего руководства в кризисных (стрессовых) ситуациях. Так, исследованию особенностей копинг-стратегий и их связи с уровнем эмоционального выгорания у менеджеров высшего звена посвящена работа С. Л. Ящук (Ящук, 2011: Электр. ресурс). В результате проведенного исследования было показано, что менеджеры высшего звена в ситуации преодоления достаточно редко используют поведение, направленное на активное устранение угрозы (только $28 \%$ респондентов), а также предназначенное для изменения стрессовых отношений с физической или социальной средой. Они чаще обращаются к интрапсихическим формам преодоления стресса, относящимся к защитным механизмам, к манипулятивным и импульсивным действиям.

В связи с этим можно предположить, что работа по формированию адекватного копинг-поведения на уровне руководителя должна включать в себя такие моменты, как: поиск смысла труда для работника и для самого себя; поиск способностей для взаимопомощи коллегам и подчиненным; поиск способностей для самосовершенствования в процессе выполнения работы; определение философии организации (своего подразделения); становление для подчиненных и коллег примером в реализации духовной составляющей труда и т. д. Важно подчеркнуть, что подобная мысль о значимости духовного аспекта в ситуациях преодоления трудностей не является новой и так же обращает на себя внимание в более ранних работах Н. Е. Водопьяновой (Водопьянова, 2009).

Копинг-стратегиям во время кризиса посвящено и исследование Н.Агазаде (Агазаде, 2012: Электр. ресурс). На основании полученных результатов Агазаде были выделены и описаны определенные рекоменда- 
ции по стабилизации применения адаптивных копингов, которые включают в себя: проведение докризисных обучающих тренингов; повышение уровня информированности сотрудников о текущих процессах в организации; обеспечение мониторинга и поддержки со стороны руководства; возможность доступа к дополнительным ресурсам (техническим, человеческим, финансовым, временным) в течение кризиса; внедрение наставничества и т. д.

Идея о возможном влиянии организационной культуры на совладающее поведение работников так же легла в основу недавнего исследования С. В. Чернобровкиной и А. С. Акамовой, которое было посвящено изучению особенностей протекания организационного стресса и совладающего поведения у сотрудников различных типов организационных культур (Чернобровкина, Акамова, 2010). Полученные авторами результаты можно обобщить в форме краткой характеристики взаимосвязей типов организационных культур и стратегий совладающего поведения: 1) Клановорыночный тип культуры положительно связан со стратегиями: поиска социальной поддержки, вступления в социальные контакты; избегания и «непрямых действий»; 2) Рыночный тип культуры отрицательно связан со стратегиями: социального контакта и социальной поддержки, и положительно со стратегиями «ассертивные действия» и «асоциальные действия»; 3) Иерархический тип отрицательно связан со стратегией «непрямые действия»; и 4) Адхократический тип положительно связан со стратегией избегания.

Важным выводом данного исследования стал и тот факт, что смешанный кланово-рыночный тип культуры сотрудники рассматривают как более удовлетворительный, нежели просто рыночный. Можно предположить, что это связано с особенностями русской ментальности, а именно с выраженностью коллективизма в отношениях и с ожиданием патернализма со стороны своих организаций.

\section{Выводы}

В заключение можно сказать, что значимость организационной культуры в ориентации относительно способов действий внутри организации в целом, и при возникновении стрессовых ситуаций - в частности, трудно переоценить. Однако повышающийся интерес к данной области исследования не исключает пробелов, противоречий или еще не изученных аспектов в данной тематике. В частности, актуальным направлением для организационных психологов как в теоретическом, так и практическом планах, будет разработка некоторой концепции по выделению основных трудных жизненных ситуаций, возникающих в рамках организации, и их 
соотнесение с возможными стратегиями преодолевающего поведения.

\section{СПИСОК ЛИТЕРАТУРЫ}

Аберкромби, Н., Хилл, С., Тернер, Б. (2004) Социологический словарь. М. : Экономика. 620 с.

Агазаде, Н. (2012) Копинг-стратегии во время кризиса [Электронный ресурс] // Medpsy.ru. URL: http://www.medpsy.ru/mprj/archiv_ global/2012_1_12/nomer/nomer01.php (дата обращения: 09.02.2016).

Водопьянова, Н. Е. (2009) Психодиагностика стресса. СПб. : Питер. 336 с.

Грачев, А. А. (2008) Психологическое проектирование производственной организации. СПб. : Ин-т практической психологии. 187 с.

Грачев, А.А. (2014) Организационный подход к формированию культуры безопасности работника // Знание. Понимание. Умение. № 1. С. 276-287.

Котик, М. А. (1989) Психология и безопасность. Таллинн : Валгус. 440 с.

Крюкова, Т. Л. (2013) Психология совладающего поведения: современное состояние, и психологические, социокультурные перспективы // Вестник КГУ им. Н. А. Некрасова. № 5. С. 184-188.

Система стандартов безопасности труда. Общие требования к системе управления охраной труда в организации [Электронный ресурс] // ГОСТы и СНИПы. База нормативных документов для бесплатного скачивания. URL: http://gostisnip.ru/dokumenty/gosty/ssbt/gost_r_12_0_006-2002_2003 (дата обращения: 16.03.2016).

Стеклова, О. Е. (2007) Организационная культура : учебное пособие. Ульяновск : УлГТУ. 127 с.

Чернобровкина, С. В., Акамова, А. С. (2010) Корпоративная культура как фактор копинг-стратегий сотрудников в ситуации организационного стресса // Вестник Омского университета. Серия «Психология». № 2. С. $52-60$.

Шейн, Э. Х. (2002) Организационная культура и лидерство. СПб. : Питер. 336 c.

Ящук, С. Л. (2011) Особенности копинг-стратегий у менеджеров с разным уровнем сформированности синдрома эмоционального выгорания [Электронный ресурс]// Здоровье специалиста: проблемы и пути решения: материалы II заочной международной научно-практической интернетконференции, проходившей в Омском государственном университете им. Ф. М. Достоевского с сентября по ноябрь 2011 года / под ред. Е. С. Асмаковец и др. Омск: Изд-во ИРООО. 194 с. URL: https://sites.google.com/ site/zdorovespecialista/home/teoria/asuk (дата обращения: 10.023.2016).

Тащи Карина Валеръевна - магистрант кафедры социальной и этнической психологии Московского гуманитарного университета. Адрес: 
111395, Россия, г. Москва, ул. Юности, д. 5. Тел.: +7 (916) 457-85-72. Эл. адрес: karina.tashchi@bostik.com. Научный руководитель - д-р психол. н., проф. А. А. Грачев.

Tashchi Karina Valer'evna, Master's Student, Department of Social and Ethnic Psychology, Moscow University for the Humanities. Postal address: 5 Yunosti St., Moscow, Russian Federation 111395. Tel.: +7 (916) 457-85-72. E-mail: karina.tashchi@bostik.com. Research advisor: Doctor of Psychology, Professor A. A. Grachev. 